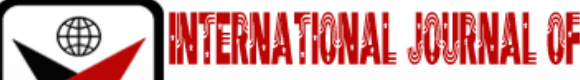

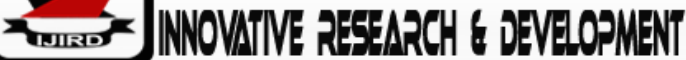

ISSN $2278-0211$ (Online)

\section{Insecticide-Laden Paint: A Promising Malaria Control Tool for Late Night Sleepers}

Olufunmilola O. Ajayi
Lecturer, Department of Biological Sciences,
Joseph Ayo Babalola University, Ikeji-Arakeji, Osun State, Nigeria
Olufunmilayo A. Idowu
Professor, Department of Pure and Applied Zoology,
Federal University of Agriculture Abeokuta, Ogun State, Nigeria
Sammy O. H. Sam-Wobo
Professor, Department of Pure and Applied Zoology,
Federal University of Agriculture Abeokuta, Ogun State, Nigeria
Ighodalo C. Eromosele
Professor, Department of Industrial Chemistry,
Federal University of Agriculture Abeokuta, Ogun State, Nigeria
Kehinde I. T. Eniola
Professor, Department of Biological Sciences,
Joseph Ayo Babalola University, Ikeji-Arakeji, Osun State, Nigeria

\begin{abstract}
:
The use of long-lasting insecticidal nets (LLINS) is the most common malaria control measure in the Tropics. LLIN target populations that can sleep under the net at mosquito biting hours. Hence, it may not be effective for people engaged in night reading, and other late-night sleepers who are exposed to mosquito bites before actually sleeping under the nets. A longitudinal study was carried out to assess the efficacy of Insecticide-Laden Paint (ILP) in the control of malaria. Bioassay was done by exposing Anopheles mosquitoes to the ILP using Poly vinyl chloride (PVC) cone for 30 minutes. Two hundred and fifty students from a boarding secondary school participated in the study. They were shared into two study groups: group 1- those who read in reading rooms painted with insecticidal paint and group 2- those who read in reading room without insecticidal paint. The prevalence of Plasmodium infection prior ILP was $19.6 \%$. The mean infection incidence among the intervention and non-intervention groups was 5.1\% and 9.5\% respectively $(P>$ 0.05). At the first quadrimester, $100.0 \%$ by 15 minutes of exposure. However, by the third quadrimester total knocked down extended to 30 minutes. The exposure of mosquito to the paint in experimental box showed preference of mosquito for alternative landing place. None of the exposed mosquitoes revived despite 24 hours in holding cup. The study shows a measure of protection while in reading room painted with insecticidal paint. The use of ILP bridges gap between dinner and bedtime.
\end{abstract}

Keywords: Malaria, Insecticide-laden paint, Late-night sleepers

\section{Introduction}

Malaria is a life-threatening blood disease caused by Plasmodium parasite capable of being transmitted from person to person by an arthropod vector, female Anopheles mosquito that carries the infective sporozoite stage of Plasmodium parasite in their salivary gland (WHO, 2016; Burkeet al., 2017; CDC, 2018a; Espinoza, 2019). The species of Plasmodium is more than one hundred in number, but the human species are four namely; Plasmodium falciparum, P. malariae, $P$. ovale and $P$. vivax. The recently discovered $P$. knowlesiis zoonotic (CDC, 2018b; WHO, 2016).

The female Anopheles mosquito thrives in warm, humid climates where pools of water provide perfect breeding grounds (UNICEF, 2000). Tropical areas have the best combination of adequate rainfall, temperature and humidity which permits breeding and survival of the vector (Mc-Wilsons et al., 1999; UNICEF, 2000; Keiser et al., 2004). Therefore, the multifaceted interactions of the vector, parasite, human host and the environment guided by different ecological and social factors help in the transmission of malaria with the risk of infection varying according to season which is usually highest at the end of, or soon after, the rainy season (Mc-Wilsons et al., 1999; Keiser et al., 2004; Daashet al., 2009; CDC, 2012). There is about 4\% increase in the estimated cases of malaria morbidity in 2018 than 2017 although there is a decrease in mortality rate (WHO, 2018, 2019). This implies that no significant progress has been achieved in reducing global malaria cases. Globally, about 266,000 children under five years old were killed by the scourge of malaria in 2017 which amount to $61 \%$ of death caused by malaria among all age groups (WHO, 2018). 
Malaria results in decreased productive capacity and increased poverty. It thus remains a major public health problem particularly in many tropical countries regardless of the intensive attempts to control it (CDC, 2012; Tustinget al., 2016). Although, the groups of people mostly at risk of this infectious disease are the children under five years, pregnant women, HIV/AIDS patients and non-immune migrants due to their weak immune system (UNICEF, 2000; Urakuet al., 2015; WHO, 2019), the inability of most people to sleep under LLIN at early biting hour makes the control intervention with LLIN seem ineffective.

About $40 \%$ of the world's children live in malaria-endemic countries where they suffer multiple episodes of malaria before they become adults (Fernadoet al., 2003; Jeremiah and Uko, 2007; Karyanaet al., 2008). Among this estimate are the students which are the raw materials for education and the primary products of educational transformations. The purpose of education is to develop the intellect of human being to meet up with social needs, create an effective workforce and contribute to the economy (Lengnick-Hall and Sanders, 1997). The scourge of malaria has a great impact in achieving this purpose. The absenteeism of students from school due to malaria attack had greatly been implicated to be responsible for poor performance in school (Brabin and Ganley, 1997; Brown et al., 2001; Kiharaet al., 2006; Fernando et al., 2010; Nankabirwa et al., 2014).

In Nigeria, malaria is a major public health disease. About $97 \%$ of the population is at risk of the infection. $P$. falciparum causes $90 \%$ of infection in Nigeria (Awololaet al., 2005, Dawakiet al., 2016). About 50\% of the adult population in Nigeria experience at least one episode of malaria annually, children under 5yrs of age experience 2 - 4 bouts. Malaria accounts for more than $60 \%$ of outpatient visit to the hospital. It also accounts for $30 \%$ and $11 \%$ childhood and maternal mortality respectively (FMOH, 2005).

Despite the widespread information, education and distribution of LLINs for malaria control, many people do not sleep under LLINs. Some people find sleeping under the LLIN uncomfortable. Some people habitually stay up late either to recreate or socialize or study. For some, the nature of their work does not allow sleeping under the net or requires they go to bed late. There is still poor access to LLIN due to insufficient supply per household and low utilization by those who possess the nets (Idowu, 2010; Auta, 2012; Aderibigbeet al., 2014; Raghavendraet al., 2017; Israel et al., 2018). Similarly, most of the children do not have access to sleeping under LLIN due to insufficient supply per household (Auta, 2012).

Moreover, the control of malaria using LLIN only works for group of people who could really sleep under it at early hours of mosquito biting periods. Likewise, there are reports of increased mosquito resistance to the pyrethroids which is the main class of insecticide recommended for treating bednets and indoor residual spray (Rubaihayoet al., 2008, Oyewoleet al., 2011; Djouaka, et al., 2016). Therefore, in the quest for a novel strategy for the control of malaria, it is important to design a convenient method that is accessible to different individuals regardless of the time they sleep at night. Hence, the essence of this research work which was designed to determine the efficacy of organophosphate-based Insecticide-laden Paints (ILP) for prevention of malaria parasite transmission, identify incidence of malaria post insecticide-laden paint control intervention among students' population and assess the waning effect of the insecticide in the paint for a year period.

\section{Materials and Methods}

\subsection{Description of Study Area}

The study was carried out in a Boarding secondary school in Ilesa, Southwestern Nigeria $\left(7^{\circ} 37^{\prime} 40.40^{\prime \prime} \mathrm{N} 4^{\circ} 44^{\prime}\right.$ 29.80"E). Ilesa is known for its agricultural potentials and lies in the rainforest of North East of Yorubaland. It has annual rainfall of over $1600 \mathrm{~mm}$ from March to early November or sometimes into December. The climate is humid tropical type with a mean annual temperature of about $28^{\circ} \mathrm{C}$ (Orimogunje et al., 2009; Agunlejika, 2014).

\subsection{Ethical Consideration and Sample Size}

Students of a boarding secondary school in Ilesa West local Government were assessed for the study. Approval for the study was obtained from the School management and ethical clearance was obtained from Osun State Ministry of Health. The sample size was calculated using Yemane (1967) method.

\subsection{Experimental Design}

A total of 250 students participated in the study. They were divided into two equal groups: group 1 (125 students) were those who read in reading rooms painted with ILP and slept under LLIN in the dormitory (intervention group) and group 2 (125 students) were those who read in reading room not painted with insecticide-laden paint and slept under LLIN in the dormitory (non-intervention group). The participants in each group were divided into five reading rooms ( 3 x 3.6 square meters each). The study was carried out from April, 2016 to March, 2017.

\subsection{Screening for Malaria Parasite}

Blood samples were collected for malaria parasite screening before the painting of the rooms with organophosphate-based ILP. The infected students were treated with artemisinin-based combination therapy.

Group 1 was distributed into five ILP painted classrooms for night readings. Group 2 were also distributed into five classrooms painted with non-ILP for night readings. A longitudinal study (three quadrimesters) of Plasmodium infection incidence post ILP painting of the classrooms was examined among the groups using microscopy method with Giemsa stain according to WHO (2001). 
Re-screening was done three months after the commencement of the usage of the classrooms for incidence of Plasmodium infection. At resumption of each term, the students were re-screened and treated if infected with malaria parasite before they were allowed to use the study locations. This was done for a session (three quadrimesters).

\subsection{Mosquito Larval Collection and Rearing}

Mosquito larvae were collected and reared as described in Ajayiet al., 2020

\subsection{Mosquito Response to the ILP Walls in Experimental box}

Three boxes were used for ILP and three boxes were used for non-ILP. The upper part of each of the box was netted to allow entry of air. Each box walls (3 replicates for each treatment) were painted with two layers of paint. Unpainted wooden rod was inserted into each of the box. Twenty-five mosquitoes were introduced into each of the box. Twenty-five Anopheles mosquitoes were released into each of the cubicle and watched for mosquito landing and resting preference. The number of dead mosquitoes at time intervals; 10, 15, 20, 30 and 40 minutes were recorded. The dead mosquitoes were placed in holding cups and supplied with cotton wool soaked with sugar solution for 24 hours. The experiment was done for three quadrimesters (WHO, 2013 mosquito susceptible test adapted).

\subsection{Statistical Analysis}

The data were analyzed with Microsoft excel 2013. Chi-Square test was used to determine the difference in the incidence of the infection among the study groups and susceptibility of the mosquito strains. Significance were measure at $95 \%$ Confidence Interval (CI). The observations were taken to be statistically significant where the P-value is $<0.05$.

\section{Results}

The study participants that protected themselves from mosquito bites during night reading using informal ways such as repellent, fan, wrappers and long socks were $63 \%$ (Figure 1). Among these people, $70.4 \%$ were infected with Plasmodium. The infection prevalence among the study population before the use of ILP was $19.6 \%$. The incidence during the ILP intervention was $10.8 \%$.

The incidence of infection was $5.1 \%$ among the intervention group while the non-intervention group had incidence of $9.5 \%$. However, the difference in infection between the groups was not significant (P > 0.5) (Figure 2). The occurrence of infection observed in the study showed that $54.4 \%$ of the intervention group was not infected throughout the study. $19.2 \%$ of none intervention group had infection thrice during the study while $4.0 \%$ of the intervention group had infection thrice $(\mathrm{P}<0.05)$ (Figure 3).

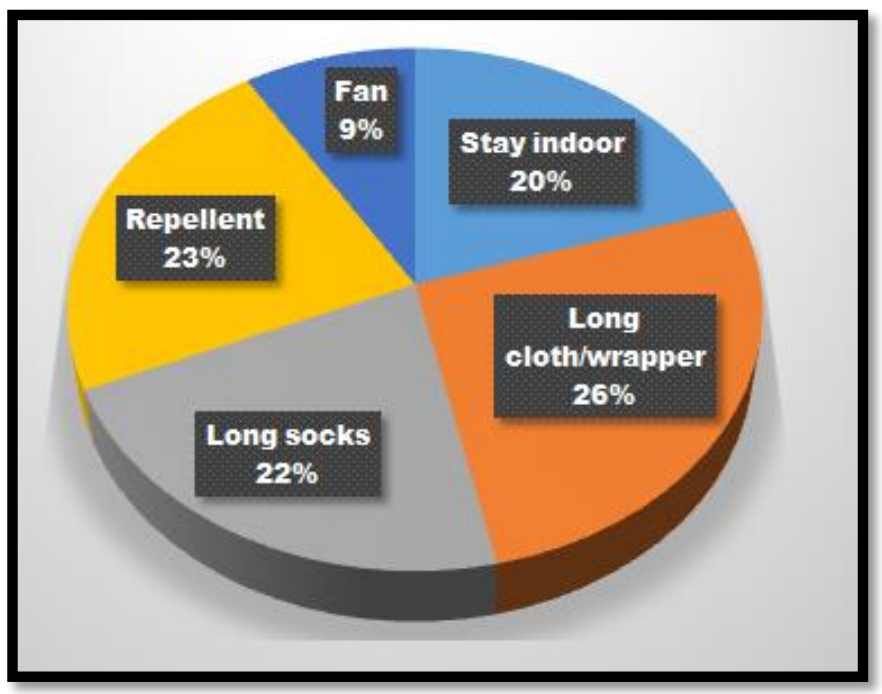

Figure 1: Informal Preventive Measure Adopted by the Study Participants before ILP Intervention 


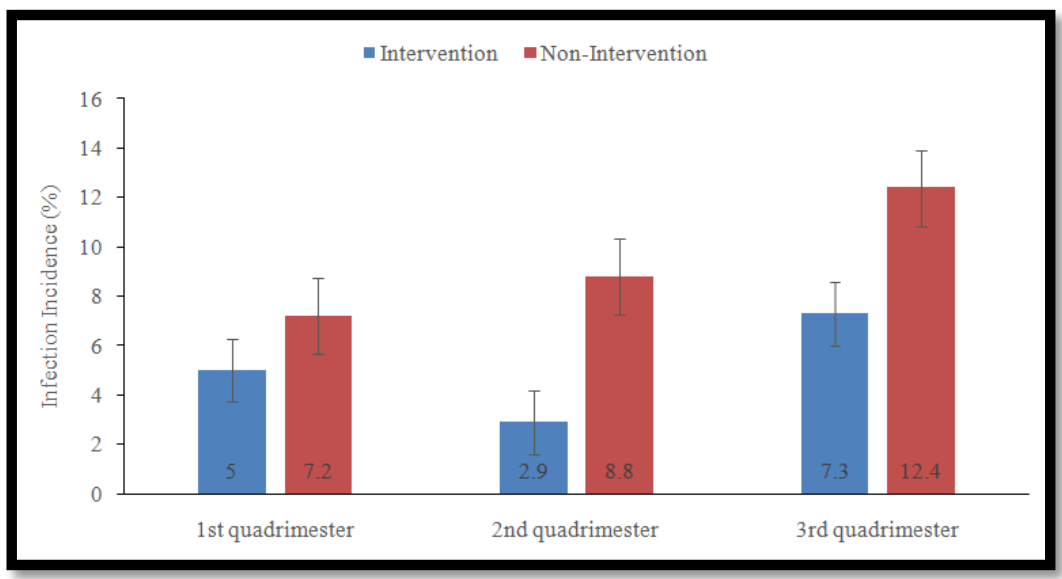

Figure 2: Longitudinal Incidence of Infection

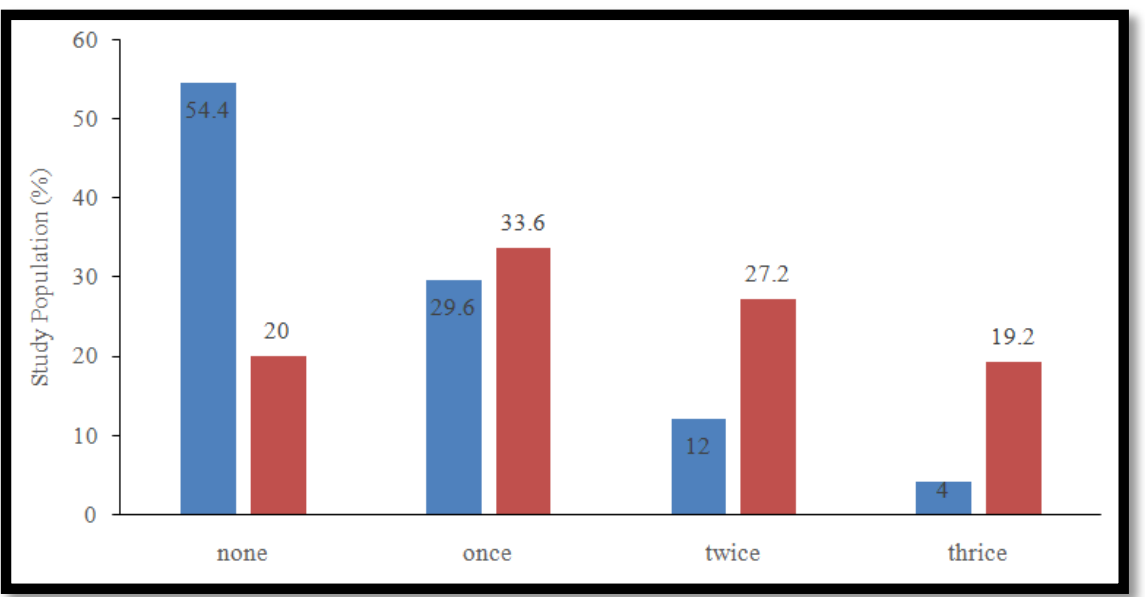

Figure 3: Infection Occurrence of the Participants during the Longitudinal Study

\subsection{Mosquito Response to Insecticide-Laden Painted Walls of Experimental Box}

The mosquitoes introduced into non-ILP box landed on the wall and rested for average of 5 minutes at a point before they flew to another point for resting (Plate 1). The reaction of the exposed laboratory reared mosquito to insecticidal painted box was shown in Figure 4.

The mosquitoes preferred resting on the floor, roof, cotton wool and unpainted rod inserted into the box. None of the exposed mosquito landed on the insecticide painted region of the box. The mosquitoes introduced into the ILP box were knocked down at intervals. However, unlike the knocked down time of mosquitoes introduced into cone bioassay; the mosquitoes were not knocked down until $15^{\text {th }}$ minutes of exposure (Figure 5). No mortality was observed among the mosquito exposed to non-ILP boxes during the experimental set-up. 


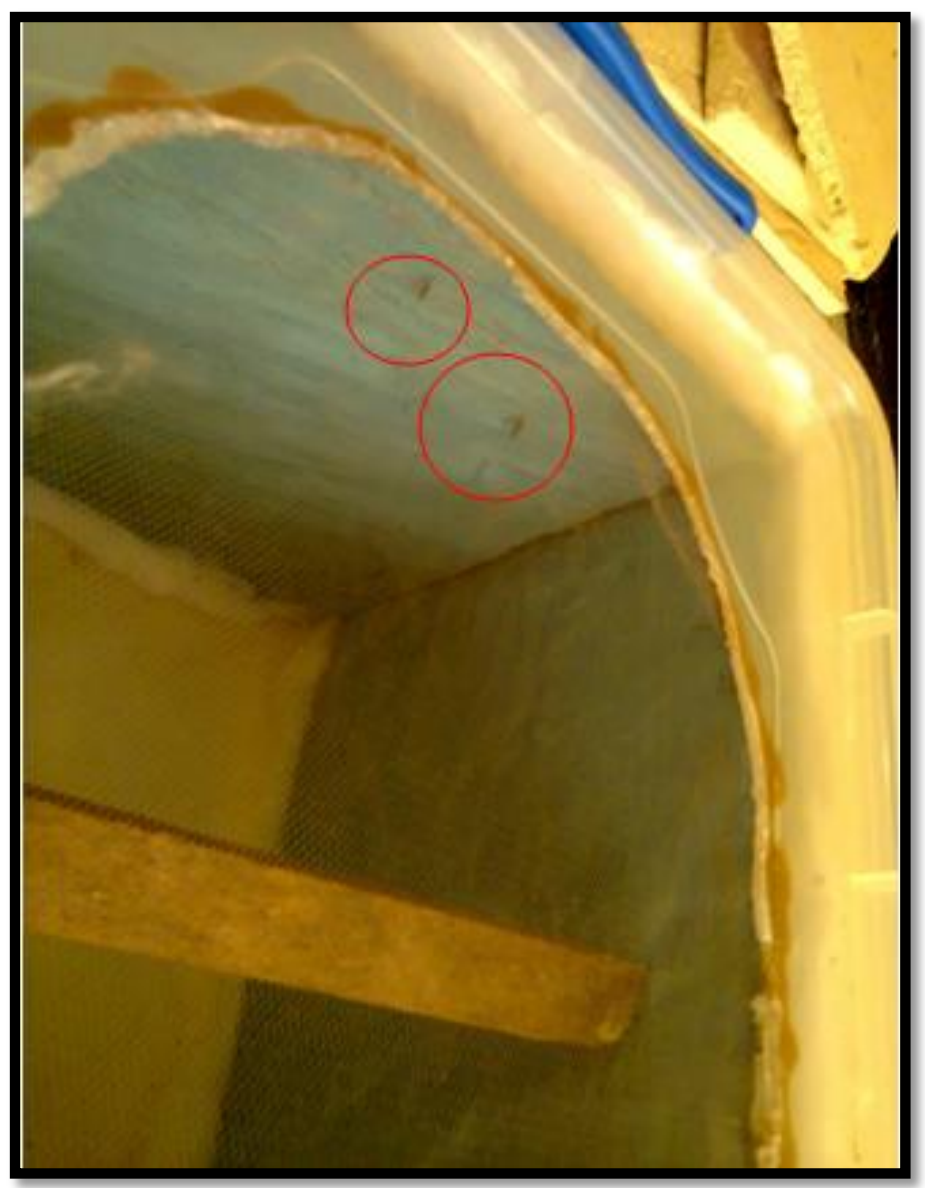

Figure 4: Anopheles Mosquito Resting on the Wall in Non-Insecticidal Painted Box

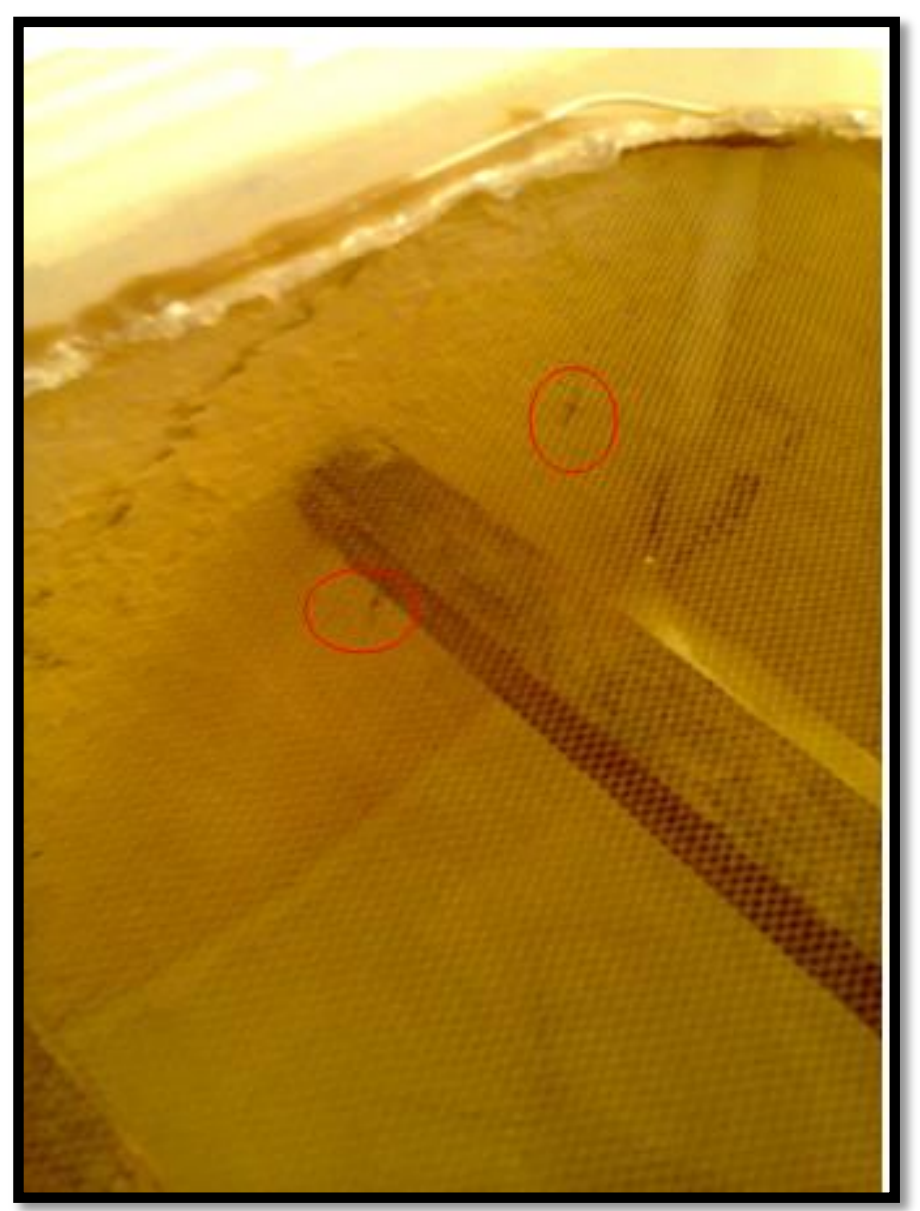

Figure 5: Alternative Resting Positions of Mosquitoes Exposed to Insecticidal Painted Box 


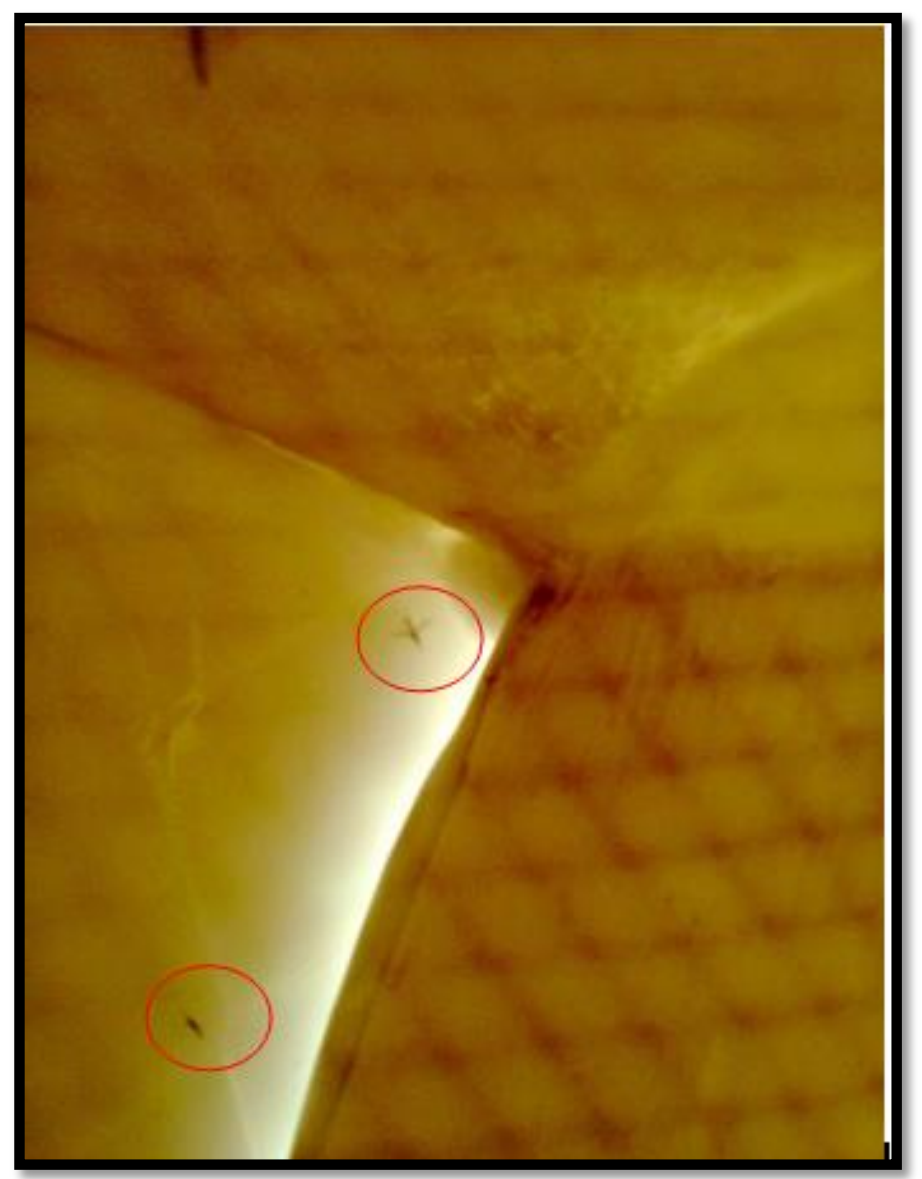

Figure 6: Dead Mosquito on the Floor of Insecticidal Paint Painted Box

\section{Discussion}

This study assessed the efficacy of organophosphate-based insecticide-laden house paint as alternative malaria control measure in view of the incessant resistance by mosquito vectors to other classes of insecticide and also to help in integrating the late-night sleepers into the malaria control measure.

The overall prevalence of Plasmodium infection in this study before the control intervention with insecticideladen paint is in consonance with the findings of Adesina (2013) and Mgbemena et al., (2016) among tertiary students' population in the northern and eastern part of Nigeria respectively although lower than what they obtained in their studies. However, this is at variance with the study carried out among students' population by Ezugbo-Nwobi (2011); Ako-Nai and Adesiyan (2012) and Adeyemo et al. (2014) where higher Plasmodium infection prevalence was obtained. The lower infection prevalence among the secondary school students could be attributed to the use of LLIN which is compulsory for secondary school students.

Despite the various informal methods of preventing mosquito bite by the students during night readings, the high percentage infection seen among these students was an indication that the methods were not effective. The protective effect of the ILP was observed in the reduction in the prevalence of infection among the study participants by the end of the longitudinal study.

Based on the control tool evaluated in this study, the incidence of infection post painting among the intervention group of this study when considered longitudinally was lower than the incidence observed among the non-intervention group. The lower infection incidence observed among the intervention group is an indication that the ILP was able to confer a level of protection on the students while reading in the classroom at night. Although a very low or no infection incidence was expected in the first quadrimester of the study being the period when the classrooms were newly painted with the ILP, an insignificant difference in infection incidence was observed between the intervention and nonintervention groups. This could probably be due to exposure to mosquito bites in the dormitories before sleeping.

Lengler (2004) opined and was also supported by WHO (2011) that the use of a large number of LLIN in a residential area helps in reduction in number of mosquitoes available which will consequently protect people directly and indirectly from having malaria. In the same vein, there might have been indirect effect of the ILP painted locations on the non-ILP locations because there was insignificant difference in the infection incidence between the two groups at the first quadrimester when compared with other two quadrimesters of the study. Probably there was reduction in the availability of mosquitoes due to lethal effect of the insecticide in the paint used for ILP painted locations and hence creating a sort of herd immunity for the non-intervention group.

This was supported in the susceptibility test where there was a hundred percent knocked down of mosquitoes exposed to ILP wall at the first quadrimester. However, the total knocked down time increased as the age of the paint increased. This showed the dwindling effect of the insecticide in the paint. The decline in the potency of the ILP could be the reason for increase in the infection incidence among the intervention group at the third quadrimester of the study 
when compared to the infection incidence at second quadrimester. The waning of the insecticide in the paint was also observed in the study conducted by Mosqueiraet al. (2015).

The infection incidence at the first quadrimester of the study was unexpectedly higher than the infection incidence at the second quadrimester. The period was at early raining season when the larvae of mosquitoes bred in pools of water were able to successfully develop to adult because they are not washed away by flood which usually results from rain fall. Probably, there was availability of mosquitoes in large quantity to successfully transmit the Plasmodium parasite. Likewise, the high infection observed at the third quadrimester happens to be the end of rainy season. Risk of infection varies according to the season. This is usually highest at the end of, or soon after, the rainy season (Mc-Wilsons et al., 1999; Keiser et al., 2004; Daash et al., 2009; CDC, 2012).

The infection incidence among the intervention groups could also be attributed to alternative landing surfaces observed in the mosquito landing experiment where the mosquitoes preferred to rest on other non-ILP surfaces. The mosquitoes could have been able to hide on non-ILP painted objects in the classrooms such as on bags, under chairs and tables where they could have opportunity of biting potential host for blood meal. It is interesting that in spite of the extension in the knocked down time as the paint age, none of the exposed mosquitoes survived despite the provision of sugar solution. This implies that contact with the ILP surface provides gradual lethal effect on the mosquito.

In conclusion, the ILP is an effective means of reducing the transmission of Plasmodium among people who could be unable to sleep under LLIN at the early biting hours of the Plasmodium vector, Anopheles mosquito. Therefore, with this intervention people in this category could be incorporated into malaria elimination intervention programme.

\section{References}

i. Aderibigbe, S. A., Olatona, F. A., Sogunro, O., Alawode, G., Babatunde, O. A., Onipe, A. I., Bolarinwa, O.A., Ameen, H. A., Osagbemi, G. K., Sanya, E. O., Olarinoye, A.O., Akande, T. M. (2014). Ownership and utilization of longlasting insecticide treated nets following free distribution campaign in south West Nigeria The Pan African Medical Journal; 17:263.

ii. Adesina, O. O. (2013). Subclinical malaria infection among University of Maiduguri students: prevalence and parasite density. Bo. Medical. Journal, 10(1):6-11.

iii. Adeyemo F. O., Okpala, P. U., Oyana, E. N. and Imoukhuede, M. O. (2014). Malaria Infection amongst Students of the University of Benin, Edo State, Nigeria. International Journal of Recent Scientific Research 5(9): 1529-1532.

iv. Agunlejika A. (2014). Brief History of Ijesaland. Summit on Industrialization of Ijesaland by Ijesa Development Foundation on $11^{\text {th }}$ November, 2014 at IBIS Hotel, 23 Toyin Street Ikeja, Lagos.

v. Ajayi, O. O.,Idowu, O.A., Sam-Wobo, S. O, Eromosele, I. C. and Eniola, K. I. (2020). Assessment of an Insecticidal Paint for Malaria Control. International journal of infection. 7(2): ei03253

vi. Ako-Nai K. A. and Adesiyan M. (2012). Unusual High Prevalence of Malaria Infection in a Tertiary Institution Setting in South-Western Nigeria. International Journal of Tropical Medicine. 7(4): 121 -129

vii. AutaA. (2012). Demographic Factors Associated with Insecticide Treated Net Use Among Nigerian Women and Children. North American Journal of Medical Sciences. 4(1): 40-44.

viii. Awolola, T.S., Oyewole, I.O., Koekemoer, L.L. and Coetzee, M. (2005). Identification of three members of the Anopheles funestus (Diptera: Culicidae) group and their role in malaria transmission in two ecological zones in Nigeria. Transactions of the Royal Society of Tropical Medicine and Hygiene 99: 525-531.

ix. Brabin B. J., and Ganley Y. (1997). Imported malaria in children in the UK. Archives of Disease in Childhood. 77:76-81.

x. $\quad$ Brown H., Rogerson S., Taylor, T., Tembo, M., Mwenechanya J., Molyneux, M., et al. (2001). Blood-brain barrier function in cerebral malaria in Malawian children. America Journal of Tropical Medicine and Hygiene 64:207213.

xi. $\quad$ Burke, A., Dandalo, L., Munhenga, G., Dahan-Moss, Y., Mbokazi, F., Ngxongo, S., Coetzee, M., Koekemoer, L. and Brooke, B. (2017). A new malaria vector mosquito in South Africa. Scientific Reports. 7:43779 | DOI: $10.1038 /$ srep43779

xii. Centre for Disease Control and Prevention (2018a). Malaria: Biology. https://www.cdc.gov/malaria/about/biology/index.html

xiii. Center for Disease Control and Prevention (2018b). Malaria. Global Health-Division of Parasitic Diseases and Malaria; www.cdcgov.gov

xiv. Center for Disease Control and Prevention (2012). History of Malaria, an Ancient Disease. Global HealthDivision of Parasitic Diseases and Malaria, www.cdcgov.gov

xv. Daash A., Srivastava A., Nagpal B. N., Saxena R., and S. K. Gupta (2009). "Geographical information system (GIS) in decision support to control malaria-a case study of Koraput district in Orissa, India," Journal of Vector Borne Diseases, vol. 46, no. 1, pp. 72-74.

xvi. Dawaki, S., Al-Mekhlafi, H. M, Ithoi, I., Ibrahim, J., Atroosh, W. M., Abdulsalam, A. M., Elyana, F. N., Adamu, A. U., Yelwa, S. I., Ahmed, A., Al-Areeqi, M. A., Subramaniam, L. R., Nasr, N. A. and Lau, Y. (2016). Is Nigeria winning the battle against malaria? Prevalence, risk factors and KAP assessment among Hausa communities in Kano State. Malaria Journal 15:351.

xvii. Djouaka, R. J., Atoyebi, S. M., Tchigossou, G. M., Riveron, J. M., Irving, H. Akoton, R., Kusimo, M. O., Bakare, A. A. and Wondji, C. S. (2016). Evidence of a multiple insecticide resistance in the malaria vector Anopheles funestusin South West Nigeria. Malaria Journal; 15: 565 
xviii. Espinoza, J. L. (2019). Malaria Resurgence in the Americas: An Underestimated Threat. Pathogens 8, 11; doi:10.3390/pathogens8010011

xix. Ezugbo-Nwobi, I. K. (2011). Prevalence of Malaria Parasites among NnamdiAzikwe University Students and Anti-Malaria Drug Use. An International Multidisciplinary Journal, Ethiopia, Vol. 5 (4):21 Pp 135 - 144.

xx. Federal Ministry of Health (2005). Public health facts. Department of Public Health. Abuja,

xxi. Fernado, S. D., Gunawaedena D. M., Bandara M. R., De Silva D., Carter R., Mendis K. N. and Wickremainghe A. R. (2003). The impact of repeated malaria attacks on the school performance of children. American Journal of Tropical Medicine and Hygiene. 69(6):582-8.

xxii. Fernando S. D., Rodrigo C., Rajapakse S. (2010). "The "hidden" burden of malaria: Cognitive impairment following infection". Malaria Journal 9:366.

xxiii. Idowu, A. O. (2010). Awareness, possession and use of insecticide-treated nets for prevention of malaria in children under five in Abeokuta, Nigeria. Journal of Paediatrics and Child Health. 47(3):117-21

xxiv. Israel, O. K., Fawole, O. I., Adebowale, A. S., Ajayi, I. K., Yusuf, O. B., Oladimeji, A. and Ajumobi, O. (2018). Caregivers' knowledge and utilization of long-lasting insecticidal nets among under-five children in Osun State, Southwest, Nigeria. Malaria Journal 17:231.

xxv. Jeremiah, Z. A. and Uko, E. K. (2007). Childhood asymptomatic malaria and nutritional status among Port Harcourt children. East Africa Journal of Public Health 4(2):55-58

xxvi. Karyana, M., Burdarm, L., Yeung, S., Kenangalem, E., Wariker, N., Maristela, R., et al. (2008). Malaria morbidity in Papua Indonesia, an area with multidrug resistant Plasmodium vivaxand Plasmodium falciparum. Malaria Journal. 7: 148.

xxvii. Keiser J, Utzinger J, Caldas de Castro M, Smith T.A, Tanner M, Singer B.H. (2004). Urbanization in sub-Saharan Africa and implication for Malaria control. America Journal of Tropical Medicine and Hygiene, 71(2): 118-127.

xxviii. Kihara, M., J. A. Carter, and C. R. J. C. Newton. (2006). The Effect of Plasmodium falciparum on Cognition: A Systematic Review. Tropical Medicine and International Health 11 (4): 386-97.

xxix. Lengler, C. 2004. Insecticide-treated nets and curtains for preventing malaria. Cochrane Database of systematic Reviews. Issue 2. DOI:10.1002/14651858.CD000363.pub2

xxx. Lengnick- Hall C. A. and Sander M. M. (1997). Designing Effective Learning System for Management Education: Students Roles, Requisite Variety and Practicing What We Teach. Academy of Management Journal 40(6): 1334-1368.

xxxi. Mc-Wilsons, W., Billing, P., Bendahmane, D. and Wijeyanratne, P. (1999). "Malaria in rural and peri-urban areas in Sub-Saharan Africa," Environmental Health Project Activity Report 71.

xxxii. Mgbemena, I. C., Ezea, C. O., Ebe, T. E., Udensi, U. J., Nwachukwu, A. A., Nzenwa, D. C. and Nwannah, A. L. (2016). Assyptomatic malaria among students of Federal University of Technology Oweri (FUTO), Imo State, Nigeria. Issues in Biological Sciences and Pharmaceutical Research. 4(6):50-57.

xxxiii. Mosqueira, B., Somab, D. D., Namountougou, M., Poda S., Diabaté, A., Ali, Q., Fournet, F., Baldet, T., Carnevale. P., Dabiré, R. K. and Mas-Coma S. (2015). Pilot study on the combination of an organophosphate-basedinsecticide paint and pyrethroid-treated long lasting nets against pyrethroid resistant malaria vectors in Burkina Faso. ActaTropica 148: 162-169

xxxiv. Nankabirwa, J., Brooker, S. J., Clarke, S. E., Fernando, D., Gitonga, C. W., Schellenberg, D. and Greenwood, B. (2014). Malaria in school-age children in Africa: an increasingly important challenge. Tropical Medicine and International Health. 19:11

xxxv. Orimogunje, O. O. I., Oyinloye, R. O., and Soumah, M. (2009). Geospatial mapping of wetlands potential in Ilesa, Southwestern Nigeria. TS 4B - SDI in FIG Working Week 2009, Surveyors key role in accelerated development, Eilat Israel. 18pp.

xxxvi. Oyewole, I. O., Ogunnowo, A. A. Ibidapo, C. A. Okoh, H. I. Awolola, T. S. and M. A. Adedayo (2011). Epidemiology of malaria and insecticide resistance burden in Nigeria. Journal of Public Health and Epidemiology Vol. 3(1), pp. 6-12.

xxxvii. Raghavendra, K., Chourasia, M. K., Swain, D. K., Bhatt, R. M., Uragayala, S., Dutta, G. D. P. and Kleinschmidt, I. (2017). Monitoring of long-lasting insecticidal nets (LLINs) coverage versus utilization: a community-based survey in malaria endemic villages of Central India. Malaria Journal 16:467

xxxviii. Rubaihayo J., Tukesiga E. and Abaasa A. (2008). Reduced susceptibility to pyrethroid insecticide treated nets by themalaria vector Anopheles gambiaes.l. in western Uganda Malaria Journal. 7:92

xxxix. Tusting, L. S., Rek, J., Arinaitwe, E., Staedke, S. G., Kamya, M. R., Cano, J. Bottomley, C., Johnston, D., Dorsey, G., Lindsay, S. W. and Lines, J. (2016). Why is malaria associated with poverty? Findings from a cohort study in rural Uganda. Infectious Diseases of Poverty. 5:78

xl. United Nations Children's Fund (2000). The global malaria burden. The Prescriber, 18:1.

xli. Uraku, A. J., Okaka, A. N. C., Ibiam, U. A., Agbafor, K. N., Obasi, N. A., Ibiam, P. M., Obasi, O. U. and Nwalo, F. N. (2015). Anitplasmodial activity of ethanolic leaf extract of Spilanthesuliginosa, Ocimumbasilicum(Sweet Basil), Hyptis Spicigera and Cymbopogoncitratus on mice Exposed to Plasmodiumberghei NK65. International Journal of Biochemistry Research and Review. 6(1):28-36.

xlii. World Health Organization (2001). Antimalarial drug combination therapy. Report of a WHO Technical Consultation, Geneva.

xliii. World Health Organization (2011). Guidelines for monitoring the durability of long-lasting insecticidal mosquito nets under operational conditions. WHO/HTM/NTD/WHOPES/2011.5 
xliv. World Health Organization (2013). Test Procedures for Insecticide Resistance monitoring in Malaria Vector mosquitoes. WHO Library Cataloguing- in-Publication Data. Pp 1 - 40.

xlv. World Health Organization (2016). World Malaria Report 2016.Geneva, Switzerland: World Health Organization.

xlvi. World Health Organization (2018). World Malaria report 2017. Global Malaria Programme World Health Organization. Geneva. Pp 1-210.

xlvii. World Health Organization (2019). Malaria, High risk group.

https://www.who.int/malaria/areas/high_risk_groups/en/ assessed 5 th August, 2019.

xlviii. Yamane T. 1967. Statistics, an Introductory Analysis. 2nd ed. Harper and Row, New York. 